\title{
Rationale for an ecological risk approach for South African water resource management
}

\author{
Sebastian Jooste ${ }^{1 *}$ and Marius Claassen ${ }^{2}$ \\ ${ }^{1}$ Institute for Water Quality Studies, Department of Water Affairs and Forestry, Private Bag X313, Pretoria 0001, South Africa \\ ${ }^{2}$ Environmentek, CSIR, Box 395, Pretoria 0001, South Africa
}

\begin{abstract}
The principle of ecosystem protection in the South African Water Act requires that water resource management tools for a multiple stressor environment be tailored to the characteristics of the aquatic ecosystem. The requirements of the Act, the characteristics of aquatic ecosystems as well as co-occurrence of diverse stressors are considered. Although single substance criteria have a useful role, they are not sufficient for resource management within the context of the ecological reserve. It is proposed that an effectlikelihood approach has the potential to address the variability and uncertainty in management of a surface water body subject to multiple stressors. An in-stream receiving water risk objective approach might be considered.
\end{abstract}

\section{Glossary}

ERA Ecological risk assessment

Hazardous Having the potential to cause an (undesired) effect.

IFR In-stream flow requirement

SAWQG South African Water Quality Guidelines

Stressor An anthropogenic substance, form of energy or circumstance that may cause a loss of sustainable ecosystem function.

\section{Introduction}

The South African national water policy considers the aquatic ecosystem to be an integral part of the resource base from which water is derived for human and environmental use, but "only that water required to meet basic human needs and maintain environmental sustainability will be guaranteed as a right. This will be known as the Reserve" (DWAF, 1997). This concept was also embodied in the National Water Act (NWA, 1998). The environmental or ecological aspect of the reserve has been identified in such a way that it must ensure water quantity and water quality which are appropriate to meet these needs. The term resource quality "is used to include the health of all parts of the water resource, which together make up an 'ecosystem', including plant and animal communities and their habitats" (DWAF, 1997).

This paper presents a rationale for the use of ecological risk in water resource management in South Africa within the context of the NWA.

\section{Background}

Two distinct philosophical approaches that can be applied to water resource quality management are summarised in Table 1.

While the approaches in Table 1 are presented as extremes in philosophy, there is a growing appreciation for the need for, and a movement toward, a holistic, integrative approach in environmental management generally and water resource management in particular

* To whom all correspondence should be addressed.

푱(012) 808-0374; fax: (012) 808-0338; e-mail: joostes@dwaf.gov.za Received 22 July 1999; accepted in revised form 23 February 2001. (e.g. Foran and Fink, 1993; EEC, 1994; Schneiders, et al., 1996; USEPA, 1997). Such a holistic approach to water resource management strongly features sustainability linked to some ecological entity (or objective) (e.g. CUWVO, 1988; Wils et al., 1994; Schneiders et al., 1995; USEPA, 1997). The ecological objectives then become either directly or indirectly the basis of, for example, water quality criteria. Ecological risk methodology can be applied to both extremes and an integrated approach and does not stand in contrast to any of these approaches.

A proposal for the application of ecological risk to the ecological reserve is shown in Fig. 1. The rationale of using ecological risk concepts in water resource management is based on three observations:

- the implications of aspects of the NWA as indicated above,

- the "diverse stressor problem" and

- the inherent characteristics of aquatic ecosystems.

\section{Implications of the NWA}

It is implicitly recognised that use of the resource is not only allowed, but is also necessary for the well-being of the country and that this use needs to be managed in a way that will ensure sustainability. In this context it is noted that:

- The terms "use" refers not only to consumption and recreational use, but also to discharge of anything that may affect, inter alia, the sustainability of use.

- The NWA makes provision for protective measures for the water resource which includes classification of the resource and setting resource quality objectives that will give effect to the reserve set for that class.

- The ecological component of the reserve refers to a quantity and quality of water that will ensure ecologically sustainable development of the resource.

- Resource quality includes the quantity, pattern, timing, water level and assurance of in-stream flow, the physical, chemical and biological characteristics of the water, the character and condition of the in-stream and riparian habitat as well as the characteristics, condition and distribution of the aquatic biota. 
TABLE 1

A comparison of a technology-based and an ecological effect-based approach to resource management

\begin{tabular}{|l|l|l|}
\hline Aspect & Technology-based approach & Ecological effect-based approach \\
\hline Point of departure & $\begin{array}{l}\text { Technology determines the best attainable } \\
\text { stressor levels. }\end{array}$ & $\begin{array}{l}\text { Ecological effect determines the most suitable } \\
\text { stressor levels }\end{array}$ \\
\hline $\begin{array}{l}\text { Characteristic } \\
\text { expressions }\end{array}$ & $\begin{array}{l}\text { Best available technology (BAT); Best available } \\
\text { technology not entailing excessive cost } \\
\text { (BATNEEC); Best management practice (BMP); } \\
\text { Best practical technology (BPT), etc. }\end{array}$ & $\begin{array}{l}\text { "Fishable and swimable rivers"; "protecting most } \\
\text { species most of the time", "maintaining sustainable } \\
\text { ecological function", etc. }\end{array}$ \\
\hline Main advantage & Proven technological feasibility. & Directly related to environmental goals \\
\hline Main disadvantage & Environmental impact largely retrospective. & $\begin{array}{l}\text { Required stressor levels not necessarily feasible or } \\
\text { viable. }\end{array}$ \\
\hline
\end{tabular}
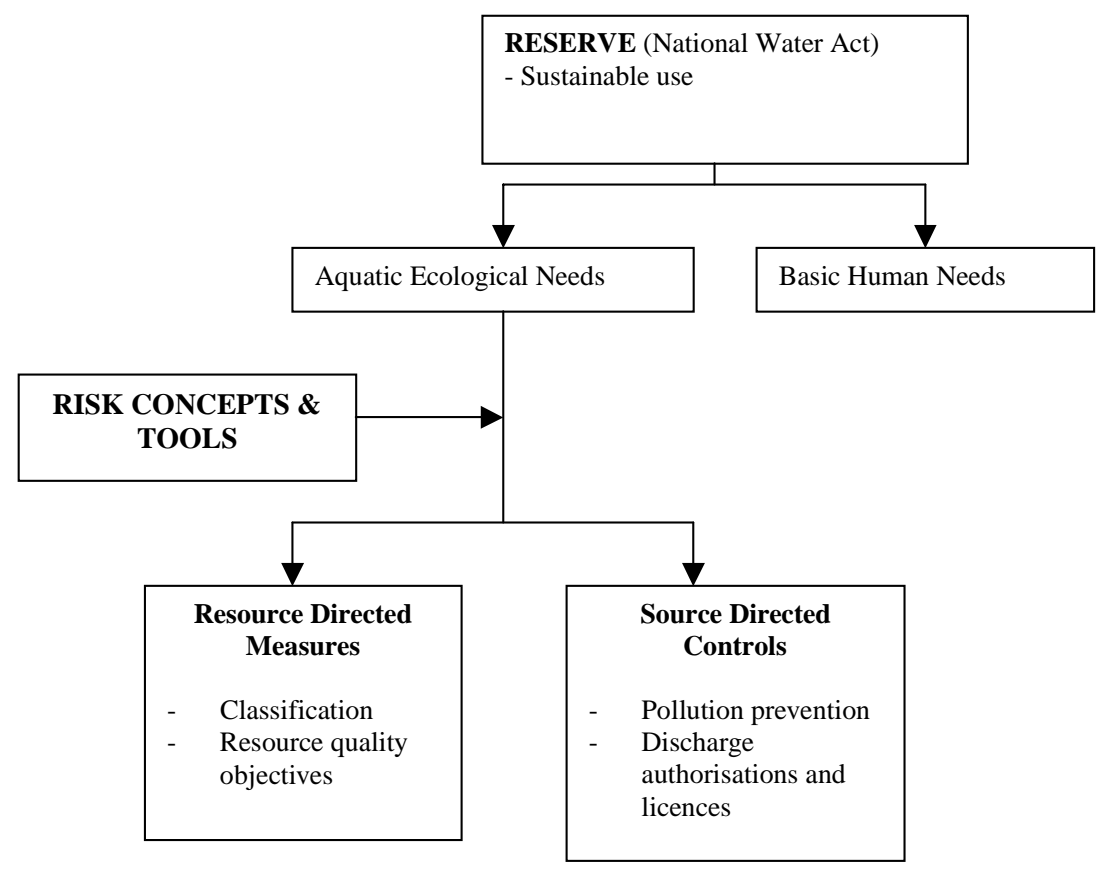

Figure 1

The potential inputs of ecological risk methodology to aspects of water resource quality management.

It is recognised that some activities that may cause stress to the aquatic ecosystem will have to be allowed, but that these have to be controlled in a manner that allows ecological sustainability.

Furthermore, the NWA differentiates between classes of resources, which correspond to a differentiation in some aspect of sustainability. Risk to the resource base was proposed as the basis of differentiation (DWAF, 1997). Here, irreversible damage to the resource base approximates a loss of sustainability.

Consequently, although the term "risk" does not appear explicitly in the NWA as the basis for classification, implicitly it is recognised that different classes of a resource will be subject to different degrees of risk of unsustainability and, by implication, different activities will result in different levels of risk.

\section{The diverse stressor problem}

Water use may entail a change in resource characteristics such as chemical composition, physical characteristics, flow and water depth (in the case of rivers), habitat for aquatic organisms, etc. The variables by which these characteristics are measured could conceivably reach a point where it has the potential to cause harm to the aquatic ecosystem.

\section{Definition of a stressor}

A stressor could be any substance or circumstance related to the aquatic environment, which could cause the aquatic ecosystem to lose sustainable ecological function. A pollutant would, by definition, be a stressor. The concept "pollutant" (in the definition of the NWA) is a subset of the concept "stressor". It should, however, be noted that a stressor may also include a set of variable values that individually would not necessarily have constituted a threat to human or aquatic life, but in combination could pose a threat. For example:

- Substances not in any way necessary for life, e.g. DDT, mercury and cadmium

- Substances necessary in the physiology of life in trace amounts (such as cobalt, zinc and copper) or in moderate amounts (such as salts and acids/alkalis) but which are either present in excess, or, chronically absent.

- Flow which is different (either higher or lower) from that which is natural to the time and place and to which organisms have become adapted over centuries.

- Modification of the in-stream habitat of organisms to a state where it is hostile to the organisms expected at the time and place.

- The presence of biota which are foreign to the time and place and which competes with indigenous biota.

- A critical combination of the first two above, which is manifested as a measurable toxic effect of unidentified origin such as estimated in whole effluent toxicity (WET). 


\section{Stressor diversity}

Each of these stressors exists because they are deemed a possible cause of a specific effect (e.g. a loss of sustainability). Consequently, any of them could result in "loss of sustainability". The diversity among ecological stressors results from a diversity in:

- Temporal and spatial scale on which stressors have an influence.

- The units in which stressors are quantified.

- The end-points that are applied to the assessment of hazards related to each stressor.

Given that the ultimate guiding principles of water resource quality management are sustainability and equity, there is a need to compare these diverse stressors. The concept of risk is proposed a suitable basis on which stressors can be compared as well as managed.

\section{Ecosystem characteristics}

A number of biologists consider ecosystems to be unpredictable or even chaotic in its behaviour (Grimm and Uchmanski, 1994). In terms of the NWA goals it is assumed that enough underlying order does exist to draw some conclusions on the response of a system to stimuli and to discount chaotic behaviour. There will still be some unpredictability and these are ascribed to three ecosystem characteristics: variability, uncertainty and vagueness (See Fig. 2).

\section{Variability}

Not only is variability commonly encountered, but organisms may be dependent on it. Hydrological conditions, seasonal cycles and variable response thresholds of individual organisms may all contribute to the survival of species. At a deterministic level, this variability may be seen as a source of unpredictability (See Fig.2)

Variability is recognised as a natural characteristic of biota (e.g. Brown, 1993; Grimm and Uchmanski, 1994; Kooijman, 1994). Several types of variability could be encountered. For example, there is a variability in individual response of the biota to a given stressor exposure (e.g. Hathway, 1984). The response variability can be represented by a cumulative response function, which expresses the cumulative fraction of the exposed population displaying a given level of response. This type of function would be analogous to the classic dose-response curve of toxicology, except that the shape of the curve need not necessarily be the same for all stressors. Although these functions may not necessarily be measurable in controlled laboratory experiments, a combination of field observation and expert interpretation is likely to provide an estimate of the stressor-response relationships. In this regard, the use of a Bayesian statistical approach rather than a strict frequentist
ECOSYSTEM CHARACTERISTICS

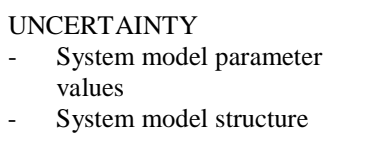

VARIABILITY

Stochasticity

System model structure

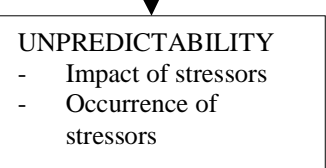




\begin{tabular}{|c|c|c|}
\hline \multicolumn{3}{|c|}{$\begin{array}{c}\text { TABLE } 2 \\
\text { Some of the characteristics of uncertainty and variability with particular reference } \\
\text { to ecological models (based on Frey, } 1993 \text { and USEPA, 1997) }\end{array}$} \\
\hline Characteristic & Uncertainty & Variability \\
\hline Source & $\begin{array}{l}\text { Lack of empirical knowledge of } \\
\text { the observer or imperfect means } \\
\text { of observation. }\end{array}$ & $\begin{array}{l}\text { True heterogeneity inherent in a well- } \\
\text { characterised population }\end{array}$ \\
\hline Impacted by: & $\begin{array}{l}\text { Model uncertainty } \\
\text { - } \text { model structure } \\
\text { - range of conceptual models } \\
\text { Parameter uncertainty } \\
\text { - } \text { random error due to imperfect } \\
\text { measurement } \\
\text { - } \text { systematic error (bias) } \\
\text { - inherent stochasticity or chaos } \\
\text { - lack of empirical basis } \\
\text { - unverified correlation among } \\
\text { - } \text { uncertain quantities } \\
\text { interpretation }\end{array}$ & $\begin{array}{l}\text { Individualism in response } \\
\text { Lack of representative data } \\
\text { Aggregation dimension (e.g. time or } \\
\text { space) }\end{array}$ \\
\hline Description & Probability distribution & Frequency distribution \\
\hline $\begin{array}{l}\text { Effect of more } \\
\text { data }\end{array}$ & Reduces & Same but more precisely known \\
\hline $\begin{array}{l}\text { Applicability of } \\
\text { standard } \\
\text { statistical data } \\
\text { analyses }\end{array}$ & $\begin{array}{l}\text { Understated (due to focus on } \\
\text { random error to the exclusion } \\
\text { of bias introduced by variability) }\end{array}$ & $\begin{array}{l}\text { Overstated (due to inclusion } \\
\text { of measurement error) }\end{array}$ \\
\hline
\end{tabular}

may be blurred. This phenomenon is exacerbated by parameter uncertainty. Even when the specific model used to predict effects is known, very often the parameter values are wholly or partially unknown or the number of parameters are unknown. Some sources of parameter uncertainty are listed in Table 2.

These observations imply that in terms of ecologically oriented water resource management, it may be practically impossible to define a specific set of conditions that can be defined as representing "unsustainability". Sustainability will be a function of an uncertain array of possibly stochastic processes. Furthermore, the assessment of sustainability is dependent on a model which is uncertain to a greater or lesser degree and which is subject to variability. The exact point at which the system loses its sustainability can not be described deterministically, but rather in terms of the probability of reaching a condition of unsustainability.

A major problem in ecological goal-driven resource management is the uncertainty in the conceptual model relating the higher level concepts (such as sustainability) to lower level management varaibles (such as quantity and quality). It involves, inter alia, uncertainty in stressor-response relationships, uncertainty in the system boundaries and the interactions within the ecosystem (See Appendix 1). Deterministic answers are often not feasible or simply impossible and so decisions have to be based on uncertain information about a variable system. This emphasises the necessity for the use of probabilistic or possibilistic tools in water resource management to ensure protection of aquatic ecosystems.

\section{Vagueness}

This is also a characteristic of the human observer, but unlike variability and uncertainty as used above, it is not related to the content of one's knowledge, but to the state or type of one's knowledge. This may result, for example, when different lines of evidence in the assessment of sustainability contribute conflicting information. While this may superficially appear to cast serious doubt on the scientific tenability of the information, this phenomenon may simply result from different levels of assessment (e.g. different spatial and temporal levels, different levels of organisation, etc.). While the solution to this problem is outside the scope of this study, it is clear that a simple determinsistic approach will be inefficient and misleading.

\section{Risk as a concept and an approach}

In a colloquial sense, risk may refer to the gravity of the consequences when a mishap occurs or the potential that an undesired outcome may result from an action. The colloquial definition emphasises the hazard (or potential of causing an effect) resulting from an event while the latter definition emphasises the probability. In both cases there is a measure of dimensionality to risk; either the description of the hazard, or the specific consequences for which the probability is estimated. 


\section{Definition of risk}

The concept of "risk" was defined in 1901 for the actuarial sciences as "the objectified uncertainty regarding the occurrence of an undesired event" (Willet, 1901, The Economic Theory of Risk and Insurance quoted by Suter, 1990, p16) or the probability of observing a specified (undesired) effect as a result of a toxic chemical exposure (Bartell et al, 1992), or, simply, the possibility of suffering harm from a hazard (Haas, 1993). For the purpose of the reserve, a definition is favoured that is essentially dimensionless: Risk is the likelihood that a loss of sustainable ecological function will occur.

This definition emphasises two important aspects:

- An a priori decision as to what the undesired event is (i.e. loss of sustainable ecological function)

- A realisation that there is uncertainty about the event which is expressed in terms of a likelihood.

It may not be possible to assess the likelihood of this event directly ('statutory risk') and it may be that the risk of surrogate events may have to be assessed ('surrogate risk') in order to assess the statutory risk.

\section{Hazards and risk}

A hazard, in contrast to risk, refers to the potential that a situation has to cause harm. The hazard is not equivalent to the risk it entails. The hazard is a characteristic of the stressor that emphasises what could happen if the ecological entity is exposed to the stressor. It does not express how likely it is to happen since that depends on the situation being assessed.

For example: An endocrine-active substance is discharged to a river. It is known to cause testicular feminisation in fish at a level of $1 \mathrm{mg} / \ell$. Its median lethal concentration for fish is about 600 $\mathrm{mg} / \ell$ but its solubility in water is limited to $15 \mathrm{mg} / \ell$. At the solubility limit it is unlikely to cause more than $10 \%$ mortality in a fish population. There are two hazards involved: mortality and population extinction through inhibition of fertility. If its concentration is managed to just below the solubility limit, the mortality risk is very low, but the population extinction risk is very high. In both cases there may be a hazard of unsustainability, but through different mechanisms. The risk will be determined by, for example, the occurrence of the substance as brief pulses followed by periods of very low concentrations, or, a fairly constant level between 1 and $15 \mathrm{mg} / \ell$. It is conceivable that the risk in the first instance is lower than that in the second instance.

\section{Expressions of likelihood}

Likelihood is used in the definition of risk because there are sources of uncertainty and variability in both the effect and the exposure components of risk. Likelihood may be expressed in terms of:

- mathematical probability which is a product of probability theory, or

- mathematical possibility which a product of fuzzy logic.

\section{Probability expression of likelihood}

For an effect $\mathrm{E}$ (e.g. loss of sustainability) the probability that $\mathrm{E}$ is true is expressed as $\mathrm{P}(\mathrm{E})$. It is customarily assumed that $\mathrm{P}(\mathrm{E})$ will have a minimum value of 0 and a maximum value of 1 .

$\mathrm{P}(\mathrm{E})$ may express either or both of two points of view:
- There is enough evidence to suggest that out of 100 repeated observation of $\mathrm{E}$, in a $100 * \mathrm{P}(\mathrm{E}) \%$ of the observations $\mathrm{E}$ will be true, or

- There is enough evidence to make the observer believe that $\mathrm{E}$ will be true $100 * \mathrm{P}(\mathrm{E}) \%$ of the time.

The difference in interpretation is that in the first case the emphasis is on the frequency that $\mathrm{E}$ is true, while in the second case the emphasis is on the confidence induced by the body of evidence suggesting $E$ to be true.

In many real ecological assessments there are not enough data from which a limiting frequency can be deduced from which $\mathrm{P}(\mathrm{E})$ can be inferred. However, there might be enough circumstantial or other indirect evidence that $\mathrm{E}$ might be true. $\mathrm{P}(\mathrm{E})$ would then express the confidence that $\mathrm{E}$ could be true.

\section{Possibility expression of likelihood}

A more serious problem than a lack of observations faces the assessment of ecological risk. The effect $\mathrm{E}$ might not be a clearly defined event. Loss of sustainability is a case in point. The loss of sustainability (or more precisely the point at which sustainability is lost) is not very clearly defined. This means that it not so easy to define $\mathrm{E}$ as being true or not. This calls for a multi-valued logic as opposed to a binary logic to express partial truth such as is found in fuzzy logic (Klir and Yuan, 1995). Possibility theory, which is based on fuzzy logic as opposed to probability theory, which is based on binary logic (Dubois and Prade, 1988) may serve well to express likelihood pertaining to the reserve. Such expression of likelihood in the context of the reserve was investigated by Jooste (2001 a).

\section{Risk and hazard approaches}

Resource management implicitly requires predictive ability for decision-making. It would not be sensible to suggest a change in a parameter value unless there is reason to believe that it will result in some advantageous effect.

In predicting or projecting an expected ecological effect there are two major aspects regarding stressors that need to be known: the way in which the target ecological entity reacts to changes in stressor level (i.e. stressor-response) and to what extent the target entity is exposed to the stressor. There are sources of unpredictability in both these aspects.

There are primarily two approaches to deal with ecological predictability problems (Fig. 2): the hazard approach and the risk approach. These approaches are both effect-based, but they differ in the way in which they deal with sources of unpredictability.

The hazard approach focuses the basis for decision-making by simplifying both the stressor-response and stressor occurrence by (necessary) assumptions. For example: the response variability, which is an inherent characteristic of the ecosystem, is simplified by selecting a stressor value that corresponds to an assumed "acceptable level of effect". This stressor value is then an assessment criterion value.

The criterion value is then interpreted to mean that all stimulus values less or equal to the criterion are acceptable, while all values above the criterion are unacceptable. The existence of a hazard is evaluated for each stressor value as it occurs.

Consequently, the hazard approach focuses both the stressorresponse and -occurrence to single numbers, which are then compared.

The risk approach generalises the basis for decision-making 


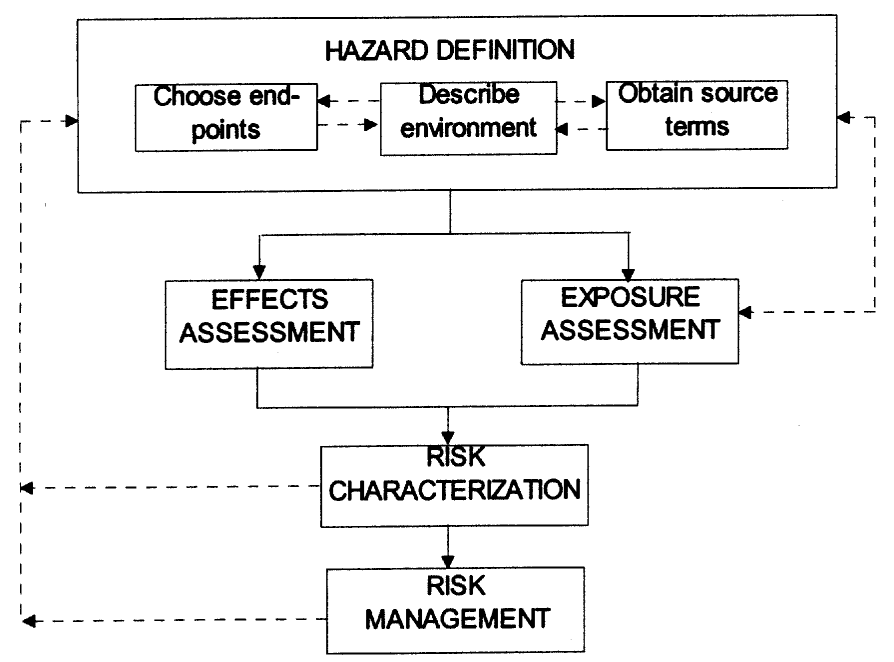

Figure 3

The basic elements of an ecological risk assessment where an ecological stressor and its source has been identified

(Suter, 1993)

by incorporating as much of the relevant evidence as possible. It uses as much as is known about the relationship between stressor and response and about the occurrence of the stressor. It recognises that there may be a continuum of response over the stressor value domain at the point or in the area where an assessment is needed.

In the context of the resource management vis-à-vis the ecological reserve, where other uses have to be weighed against reserve goals, a risk approach might well be more flexible than a hazard approach.

\section{Ecological risk assessment}

Risk assessment is an array of techniques that is primarily concerned with the estimation of the likelihood and magnitudes of events. The likelihood element implies that in principle there is a continuum of risk from infinitely small (practically zero) to very high (practically certain). Due to practical limitations, coarser resolution (e.g. small, moderate, or high) is also used. It has become one of the most widely used techniques in environmental decision-making under uncertainty and has been the subject of intensive investigation by both the USEPA and the American National Research Council (NRC, 1994; USEPA, 1998). Protocols for both environmental and ecological risk assessments have been well-established.

Protocols for the assessment of ecological risk (ERA) have been produced by various organisations such as the USEPA. The basic elements of the ecological risk assessment process are outlined in Fig. 3 and discussed below. A generic adaptation of the USEPA protocol for South African environmental assessment and a more extensive discussion of the elements of an ERA have been produced by Murray and Claassen (1999).

There are a number of features of ERA that need to be considered in applying the methodology in water resource management:

- ERA can be performed at various levels of sophistication depending on the management need and the data input quality. The assessment ranges from qualitative through point estimates to full probabilistic assessments.
- The management goal under the NWA (and, therefore, the statutory end-point) for ERA is loss of sustainability. Assessing the satutory risk is usually difficult since it is unlikely that data will generally be available to assess the likely loss of sustainability in any given stressed aquatic ecosystem. It is more likely that data relating to lower level phenomena are available. A conceptual model (such as the example in Appendix 1) is required to project the uncertainty in loss of sustainability from knowledge of the measurable parameters. Such a projection model will relate the surrogate risk to the statutory risk.

- Each stressor risk can be assessed separately and aggregated later. Jooste (2000) and Jooste (2001) investigated a model for aggregating the risk for a number of diverse stressors.

- The ERA process explicitly makes provision for consultation with parties outside the management group. The NWA makes provision for public comment on the reserve. This affords the opportunity to consider a variety of opinions on the reserve. The ERA process also allows for consideration of specific values outside of the scientific opinion inherent in the process.

\section{Discussion}

A hazard-based precautionary approach might be administratively ideal. A pragmatic version of a hazard approach was suggested by Van der Merwe and Grobler (1990) by using the pollution prevention approach for hazardous chemicals and the receiving water quality objectives (RWQO) approach for the non-hazardous substances. In terms of the ecological reserve, the distinction between hazardous and non-hazardous is difficult and the aggregation of diverse stressors is not possible with RWQOs. In addition, using hazardbased RWQOs (e.g. those based on the South African Water Quality Guidelines (SAWQG, 1997)) does not allow for effectbased management as implicitly required under the NWA. While the principle of using in-stream objectives is sound, greater benefit would derive from using risk-based objectives (See Appendix 2).

The implication of the NWA, stressor diversity and the characteristics of the ecosystem allow for the use of an ecological risk approach because of its formulation in terms of likelihood. In particular, it is noted that:

- The NWA requires sustainable use. This implies that use of the resource needs to be balanced against its protection. A hazard approach to water resource management tends to be inflexible when use is permitted (or even encouraged). This is because only some of the stressor effect information and some of the stressor occurrence information are used to assess resource status. On the other hand, a risk approach allows more of both effect and occurrence data to be used.

- The diversity of stressors that impact on the aquatic ecosystem cannot be handled in an integrated fashion by a hazard approach. Commonly, a hazard will be defined in terms of stressor measuring units such as concentration, flow rate, etc. A hazard approach does not inherently allow for ranking stressors or managing for combined effect. A risk approach has the advantage of placing stressors on a common, practically unitless basis.

- The characteristics of the ecosystem and our knowledge of it such as the necessity of variability and the epistemic uncertainty mitigates against making any information regarding the system and its response to stressors redundant. Such redundancy is 
necessarily a part of the hazard approach to resource management. The risk approach, by contrast, tends to be less wasteful of available data.

The use of risk does not preclude a precautionary approach. Precaution is introduced by, for example, conservative assumptions or policies regarding:

- Risk acceptability criteria (what levels of risk are acceptable for each class)

- Acceptability of stressor-effect data (e.g. rejecting data that suggest questionably high tolerance)

- Stressor occurrence estimation (e.g. not accepting stressor degradation for conservative substances)

Although risk assessment may yield continuous assessments, setting risk acceptability criteria could generate dichotomous assessments. Such criteria may comprise of:

- a de minimis risk criterion, i.e. a criterion that indicates that the risk is too small to be of any concern and the situation that gives rise to it does not need serious attention, and

- a de manifestis risk criterion, i.e. a risk that is unacceptably large and the situation that gives rise to it, one that is unacceptable.

In the present context, where risk is descriptive of a viewpoint of an observer, both de minimis and de manifestis risk are more likely to be generated in the water resource management policy domain than in a strictly scientific domain. The range between the de minimis risk value and the de manifestis risk value can be divided into an arbitrary number of values to correspond with the resource classification required under the NWA. These would then give rise to resource risk objectives (RROs).

The RROs would then reflect the aggregate risk of all stressors in the resource (as defined in the definition of the reserve). These RROs could then be used to derive site-specific resource quality objectives that take cognisance of the local surrogate risk parameters as well as the characteristics of the known stressor sources in a catchment. An example of this is given in Jooste (in press).

\section{Conclusions}

Ecological risk could serve as a useful approach in certain aspects of water resource management. Interpreting resource classification, as required in the NWA, on a risk base, will assist in deriving resource quality objectives that are both efficacious and flexible.

An ecological risk approach is not a panacea for water resource management. It requires consideration of the scientific data and its relation to human values. It reduces decisions from a purely mechanical process to one that requires explicit action. While this may be difficult in some situations, it increases the flexibility and transparency of the catchment management process while simultaneously assuring that the goal of protection of the ecosystem is attained to the extent possible.

Risk as a tool, although not exclusively dedicated to, is best applied in a risk management framework. In such a framework the objective of risk based decision-making would be to balance the degree of risk to be permitted against the cost of risk reduction (not necessarily only in monetary terms) or against competing risks.

- Formulating a policy for the use of risk-based methods which should serve both to guide the development of an ecological risk assessment ethic in South Africa (e.g. it would address the perception that using risk is merely an excuse for doing nothing (Tal, 1997)).

- Developing a framework for risk-based resource quality management and synthesising this with the current institutional framework.

- Defining and evaluating an acceptable risk range bounded by the de manifestis and de minimis risks.

- Discretising the acceptable risk range in keeping with the classification of water resources and formulating realistic riskbased objectives in keeping with the ecological reserve.

- Investigating methodologies from the information sciences by which the scarce data and expert knowledge can be brought together to produce the information, particularly the stressor response information, needed to calculate the stressor specific risk.

\section{Acknowledgements}

The stimulating discussions with a number of colleagues and the critical review of earlier versions of the manuscript by Drs. Heather MacKay and Henk van Vliet is gratefully acknowledged as is the permission by the Department of Water Affairs and Forestry to publish this paper.

\section{References}

BARTELL SM, GARDNER RH and O'NEILL RV (1992) Ecological Risk Estimation. Lewis Publishers, Chelsea, Michigan.

BROWN AC (1993) Variability in biological systems. S.Afr. J. Sci. 89 308-309.

CALAMARID and VIGHIM(1992) A proposal to define quality objectives for aquatic life for mixtures of chemical substances. Chemosphere $\mathbf{2 5}$ (4) $531-542$

CANALE RP and SEO D-I (1996) Performance, reliability and uncertainty of total phosphorus models for lakes-II. Stochastic analyses. Water Res. 30 95-102.

CHAPMAN PM, FAIRBROTHER A and BROWN D (1998) A critical evaluation of safety (uncertainty) factors for ecological risk assessment. Environ. Toxicol.Chem. 17 99-108.

CRABTREE RW, CLUCKIE ID and FORSTER CF (1987) Percentile estimation for water quality data. Water Res. 21 583-590.

CRANE M and GODOLPHIN E (2000) Statistical Analysis of Effluent Bioassays. R\&D Technical Report E19, Environment Agency, Almondsbury, Bristol, UK.

CRUMP KS (1984) A new method for determining allowable daily intakes. Fundam. Appl. Toxicol. $4854-871$.

CUWVO, Coördinatiecommissie Uitvoering Wet Verontreiniging Oppervlaktewateren. (1988). Ecological Quality Objectives for Surface Waters in the Netherlands. Utrecht.

DEFINETTI B (1990) Theory of Probability 1. Wiley Interscience, John Wiley and Sons, Chichester. 300 pp.

DELEO GA and LEVIN S (1997) The multifaceted aspects of ecosystem integrity. Conservation Ecology 1(1) (www.consecol.org/vol1/iss1/ art3).

DICKENS CWS and GRAHAM PM (1998) Biomonitoring for effective management of wastewater discharges and health of the river environment. Aquat. Ecosyst. Health Manage. 1 199-217.

DUBOIS D and PRADE H (1988) Possibility Theory: An Approach to the Computerized Processing of Uncertainty. Plenum Press, New York. $263 \mathrm{pp}$.

DWAF (1997) White Paper on a National Water Policy for South Africa. Department of Water Affairs and Forestry, Pretoria, South Africa.

EEC (EUROPEAN ECONOMIC COMMUNITY) (1994) Proposal for a Council Directive (EEC) on the Ecological Quality of Water, Submitted by the Commission on 8/7/94. Report 94/C 222/6-15.

FORAN JA and FINK LE (1993) Regulating Toxic Substances in Surface Water. Lewis Publishers, Boca Raton. $171 \mathrm{pp}$. 
FREY HC (1993) Separating variability and uncertainty in exposure assessment: Motivations and method. Paper 93-RA-116A.02 presented at the Air \& Waste Manage. Assoc. $86^{\text {th }}$ Ann. Meet., Denver, Colorado, June 13-18, 1993.

GRIMM V and UCHMANSKI J (1994) Ecological systems are not dynamical systems: some consequences of individual variability. In: Grasman J and Van Straaten G (eds.) Predictability and Nonlinear Modelling in Natural Sciences and Economics. Kluwer Academic Publishers. 248-259.

HAAS CN (1993) Risk assessment as a standard setting tool. WQI 4 30-32.

HATHWAY DE (1984) Molecular Aspects of Toxicology. The Royal Society of Chemistry, London.

JOOSTE S (2000) A model to estimate the total ecological risk in the management of water resources subject to multiple stressors. Water $S A$ 26 (2) $159-166$

JOOSTE S (2001) A possibilistic approach to diverse stressor aquatic ecological risk estimation. Water SA 27 (3) 293-302.

JOOSTE S (In press) Ecological concern as a factor in the optimal attenuation of diverse stressor sources in a stream. Accepted for publication in Water Sci.Technol.

KAPOOR V, GELHAR LW and MIRALLES-WILHELM F (1997) Bimolecular second-order reactions in spatially varying flows: Segregation induced scale-dependent transformation rates. Water Resour. Res. 33 527-536.

KLIR GJ and YUAN B (1995) Fuzzy Sets and Fuzzy Logic: Theory and Applications. Prentice Hall Inc.

KOOIJMAN SALM (1987) A safety factor for LC50 values allowing for differences in sensitivity among species. Water Res. 21 269-276.

KOOIJMAN SALM (1994) Individual-based population modelling. In: Grasman J and Van Straaten G (eds.) Predictability and Nonlinear Modelling in Natural Sciences and Economics. Kluwer Academic Publishers.

MURRAY K and CLAASSEN M (1999) An interpretation and evaluation of the US Environmental Protection Agency ecological risk assessment guidelines. Water SA 25 (4) 513 - 518.

NOVOTNY V, FEIZHOU L and WAWRZYN WG (1994) Monte Carlo modeling of water and sediment contamination by toxic metals at the North Avenue Dam, Milwaukee, WI, USA. Water Sci. Technol. 30 109-119.

NRC (NATIONAL RESEARCHCOUNCIL) (1994) Science and Judgment in Risk Assessment. National Academy Press, Washington, DC.

NWA (1998) National Water Act (No. 36 of 1998). Government Gazette Volume 398 No 19182. Government Printer, Pretoria, South Africa.

OECD (1996) Draft Report of the OECD Workshop on Statistical Analysis of Aquatic Toxicity Data, Braunschweig, Germany, 15-17 October, 1996. Organisation for Economic Cooperation and Development, Paris.
O’NEILL RV, ELWOOD JW and HILDEBRAND SG (1979) Theoretical implications of spatial heterogeneity in stream ecosystems. In: Innis GS and O'Neill RV (eds.) Systems Analysis of Ecosystems. 79-101.

RAPPORT DJ, REIGER HA and HUTCHINSON TG (1995) Ecosystem behaviour under stress. Am. Nat. 125 (5) 617-640.

ROUX DJ, JOOSTE SHJ and MACKAY HM (1996) Substance-specific water quality criteria for the protection of South African freshwater ecosystems: Methods for derivation and initial results for some inorganic toxic substances. S. Afr. J. Sci. 92 198-206.

SAWQG (1997) South African Water Quality Guidelines 7: Aquatic Ecosystems. Dept. of Water Affairs and Forestry, Pretoria, South Africa.

SCHNEIDERS A, WILS C and VERHEYEN RF (1995) Research on the Distribution and Typology of Ecologically Valuable Water Courses in Flanders. Flemish Administration (AMINAL).

SCHNEIDERS A, WILS C, VERHEYEN RF and DE PAUW N (1996) Ecological water quality objectives, a useful frame of reference for ecological impact assessment?, Eur. Water Pollut. Control 6 8-16.

SHINE JP, IKA RV and FORD TE (1995) Multivariate statistical examination of spatial and temporal patterns of heavy metal contamination in New Bedford harbor marine sediments. Environ. Sci. Technol. 29 1781-1788.

STEINHORST RK (1979) Stochastic difference equation models of biological systems. In: Innis GS and O'Neill RV (eds.) Syst. Anal. Ecosyst. 1-22.

SUTER GW(II) (1990) Environmental risk assessment/environmental hazard assessment: Similarities and differences. In: Landis WG and Van der Schalie WH (eds.), Aquatic Toxicology and Risk Assessment: Vol. 13 ASTM STP 1096, American Society for Testing Materials, Philadelphia. 5-15.

SUTER GW(II) (1993) Ecological Risk Assessment. Lewis Publishers, Boca Raton.

TAL A (1997) Assessing the environmental movement's attitudes toward risk assessment. Environ. Sci. Technol. 31 470A-476A.

USEPA (1997) Priorities for Ecological Protection: An initial List and Discussion Document for EPA.EPA/600/S-97/002, U.S. Environmental Protection Agency, Washington, DC.

USEPA (1998) Guidelines for Ecological Risk Assessment. Report EPA/ 630/R-95/002B, Risk Assessment Forum, U.S. Environmental Protection Agency, Washington, DC.

VAN DER MERWE W and GROBLER DC (1990) Water quality management in the RSA: Preparing for the future. Water SA 16 (1) 49-53.

WILS C, SCHNEIDERS A, BERVOETS L, NAGELS A, WEISS L and VERHEYEN RF (1994) Assessment of ecological value of rivers in Flanders (Belgium). Water Sci. Technol. 30 37-47.

\section{Appendix 1 \\ A conceptual model for end-point projection}

It is unlikely that data will generally be available to assess the likely loss of sustainability in any given stressed aquatic ecosystem. It is more likely that data relating to lower level phenomena are available. A conceptual model is required to project the uncertainty in loss of sustainability from knowledge of the measurable parameters. A phenomenological inference model for the ecological reserve with a precautionary approach may be based on the following postulates:

- The reference state for the model is the pristine system. The pristine system has all the characteristics (including the potential for sustainable use) that could be wished for. It is assumed that the reference state's only fixed characteristic is its 'degree of correspondence to the pristine state', but that the values of the descriptors used to characterise this state would be spatially and temporally variable.

- For a system that is managed to be under constant stress (as most South African surface water systems are due, to the semi- arid nature of most of the country), integrity (and by implication resilience) is lost more easily than in a comparable system subject to infrequent high intensity stress (Rapport et al.,1995). This means that both acute (in the sense of high-level shortduration) stress, and chronic (in the sense of low-level longduration) stress should be addressed in resource management. - It is provisionally assumed that a specific point exists where the sustainability of the system is lost (the system 'crashes' with respect to sustainable use). This point is generally unknown, but the likelihood of approaching this point can be assessed on a "grey scale". The uncertainty in describing this point is similar in the uncertainty in the critical level of loss of integrity that corresponds to this point. The state of integrity of the system is determined by its state of biodiversity and the deviation from the natural temporal and spatial patterns of flow and water chemistry. 


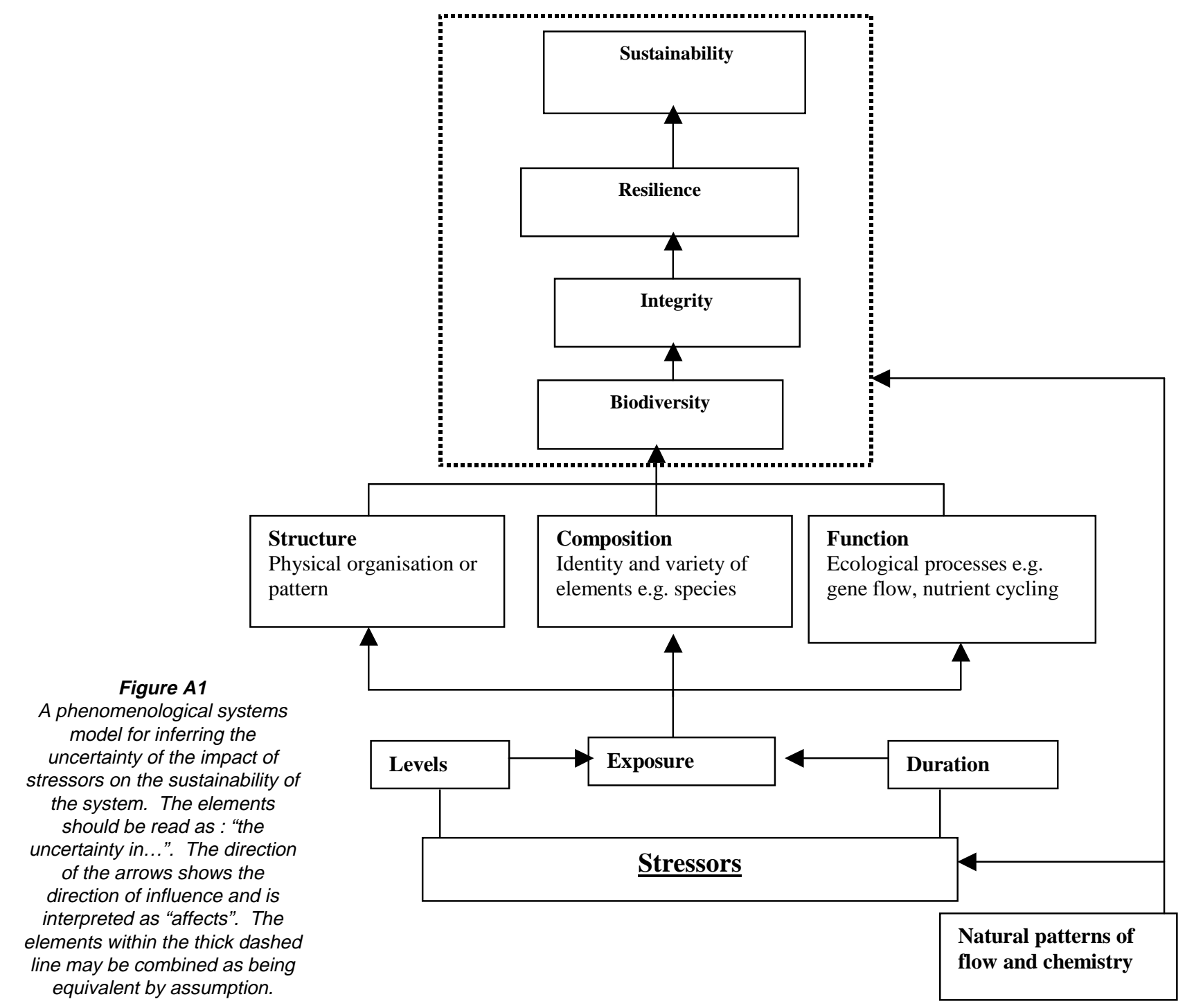

- Biodiversity is dependent on the composition, structure and function of the system (each at several levels of organization from molecular to landscape level) in relation to what it could have been in an undisturbed, pristine system. Biodiversity as a variable indicating stress is subject to an interpretation of the individual importance of species. Redundancy is possible or even probable in an ecosystem and the real question is how much redundancy could be lost without pushing the system to the edge of some irreversible, catastrophic change (DeLeo and Levin, 1997). The conservative assumption would be that all species are equally important and that loss of species systematically undermines integrity.

- A further precautionary assumption is that the system under consideration is isolated and repopulating from refugiae outside the borders of the system is impossible.
A conceptual phenomenological model based on these postulates is presented in Fig. A1. In this model the arrows indicate how the uncertainty in one variable affects the uncertainty in another. The elements within the thick dashed line are assumed to be logically equivalent in the sense that the epistemological uncertainty in the impact of one on the other is similar. This assumption need of course not hold if more specific information is available.

Each of the propositions regarding impact (represented by the arrows in Fig. A1) of this conceptual model is based on a sense of expectation founded on the assessor's knowledge base, experience and perception of the specific situation being assessed.

Logically, the certainty in a higher level variable cannot be higher than that of a lower level variable. This means that there is a greater uncertainty in the statutory risk than in the surrogate risk. This model helps the assessor to select an end-point and the same time to describe the uncertainty in the risk assessment goal. 


\section{Appendix 2 \\ A risk interpretation of the current SAWQG criteria}

Suppose a specific effect gives rise to an event $E$ in an ecosystem that is subject to $n$ different stressors. In general, each different stressor $i$ will give rise to $E_{i}$. The combined probability of effect is given by (DeFinetti, 1990):

$$
\begin{aligned}
P(E)= & P\left(\bigcup_{i=1}^{n} E_{i}\right)=\sum_{i} P\left(E_{i}\right)-\sum_{i, j} P\left(E_{i} E_{j}\right)+\sum_{i, j, h} P\left(E_{i} E_{j} E_{h}\right) \\
& -\ldots \pm P\left(E_{1} E_{2} \ldots E_{n}\right)
\end{aligned}
$$

where $P(A B)$ denotes the probability of the conjunction of $A$ and $B$. The form of $P(A B)$ depends on the independence of $A$ and $B$. In the case where the occurrence of $A$ is logically independent of $B$, then $P(A B)$ is expressed as $P(A) P(B)$. The resulting boundaries on the effect probability is given by Eqs. (A2).

$$
\max _{i}\left\{P\left(E_{i}\right)\right\}<P(E) \leq \sum_{i} P\left(E_{i}\right)
$$

A safety factor $\gamma_{i}$ where $\left(\gamma_{i} \geq 1\right)$ applied to a risk is $a_{i}$ for stressor $i$ to accommodate uncertainty of some kind, then the implied risk $b_{i}$ for stressor $i$ is: $b_{i}=a_{i} / \gamma_{i}$. If the individual stressor risks are assumed to be logically independent, then, from Eq. (A1), the total risk can be expressed as Eq. (A3).

$$
P(E)=\sum_{i} \gamma_{i} b_{i}-\sum_{i, j} \gamma_{i} \gamma_{j} b_{i} b_{j}+\ldots<\sum_{j} \gamma_{i} b_{i}
$$

Comparing the situations where there are $n$ different stressors present to the one where there are $m$ different stressors:

$$
\frac{P(E)_{n}}{P(E)_{m}}<\frac{\sum_{i=1}^{n} \gamma_{i} b_{i}}{\sum_{i=1}^{m} \gamma_{i} b_{i}}
$$

If $m>n$ then the right-hand side of Eq. (A4) is less than one if $\gamma_{i}$ is constant. This implies that if a constant safety factor is used in the derivation of criteria, the total risk to the ecosystem increases as the number of (potentially) additive stressors increase. Alternatively, if a constant total risk is assumed (which should be independent of the number of stressors) then the risk ratio should be 1 and, therefore, Eq. (A4) becomes Eq. (A5):

$$
\sum_{i=1}^{m}{ }^{m} \gamma_{i}{ }^{m} b_{i}<\sum_{i=1}^{n}{ }^{n} \gamma_{i}{ }^{n} b_{i}
$$

If the safety factor is to be independent of the stressor and the individual stressor risk levels are constant then ${ }^{\mathrm{m}} \gamma>{ }^{\mathrm{n}} \gamma$, which means that the safety factor is dependent on the number of stressors if the total risk is to kept constant.

In the derivation of the current SAWQG criteria provision is made for a target water quality range (TWQR, abbreviated to T), a chronic effect value (CEV, abbreviated to $\mathrm{C}$ ) and an acute effect value (AEV, abbreviated to A) (Roux, et. al., 1996; SAWQG, 1997). Although risk is not the explicit basis for derivation, each of these implictly represent a risk $a_{i}, c_{i}$ and $t_{I}$ respectively. By definition $c_{i}>t_{i}$, but there is no way of comparing $a_{i}$ and $c_{i}$ directly since they refer to different end-points.

There is an implicit maximum total acceptable risk of effect $E$ of $\max \left\{a_{i}, c_{i}\right\}$ for any single substance $i$. If the management goal is that the substance concentrations are lower than the criterion values, then from Eq.(A2) the total risk, $P(E)$, will be expressed as in Eq (A6).

$$
\begin{aligned}
& P\left(E_{A}\right) \leq \sum_{i=1}^{n} a_{i} \\
& P\left(E_{C}\right) \leq \sum_{i=1}^{n} c_{i}
\end{aligned}
$$

If all the stressors acted independently then, in which case the implicit risk condition is met. However, if stressors $k$ and $l$, for example, interact with the target organisms by some common mode of action, so that their effect is additive in some way (Calamari and Vighi, 1992), then the probability of their combined effect can be expressed in terms of the joint probability, say $P\left(E_{A} / A_{k} A_{l}\right)$ which, according to Eq. (A3), will always be larger than $\max \left\{a_{k}, a_{l}\right\}$.

This means that if:

- There is any additivity of effect among the stressors present and management up to the criterion levels allowed for each stressor, then the probability of combined effect will be larger than the implied maximum acceptable effect probability. Consequently, management of stressor levels up to the criterion values will logically result in an "unacceptable" level of effect.

- Safety factors had been applied in the derivation of the criteria (Kooijman, 1987), so that the actual risk implied by the criteria is less than the acceptable risk, then the margin of safety afforded by these safety factors depends on the number of stressors assumed to be present (Eq. (A5)). Chapman et al., (1998) point out that current application of safety factors is largely a matter of policy and not of empirical science and that injudicious use may result in useless overprotection. 